\title{
RESEARCH ON THE ATTITUDE AND THE PROFESSIONAL TRAINING OF GENERAL PRACTITIONERS AND NEONATOLOGISTS IN VARNA DISTRICT, CONCERNING IMMUNOPROPHYLAXIS IN THE REPUBLIC OF BULGARIA
}

\author{
E. Ivanova*, R. Konstantinov, A. Kircheva, S. Staneva \\ Department of Hygiene and Epidemiology, Faculty of Public Health, Medical University, \\ Varna, Bulgaria
}

\begin{abstract}
Introduction: The hesitation and mistrust of the population to vaccines hamper the implementation of national immunization programs. The active and competent participation of medical specialists involved in the implementation of the immune prophylaxis is necessary for the formation of proper attitude of society towards immunizations.

The objective of the present research is to investigate the attitude and professional training of general practitioners and neonatologists in Varna District concerning immunoprophylaxis in the Republic of Bulgaria

Materials and Methods: Subject of the research are 127 respondents divided into two groups: 113 general practitioners (GPs) and 14 neonatologists from Varna district. Sociological and statistical methods for analysis and presentation of results were used.

Results and discussion: GPs and neonatologists believe that vaccines included in the Immunization Calendar of the Republic of Bulgaria should be mandatory. Over 70\% of them reported that they had in their hands persons and parents who refused immunizations. The medics' confidence in the safety and effectiveness of vaccines helps them to communicate with their parents, but over half of the respondents express the need for continuous postgraduate training in immune prophylaxis. The awareness of medical professionals will increase public confidence of society in vaccines and will benefit public health, dramatically reducing morbidity and mortality from vaccine-preventable diseases.
\end{abstract}

Key words: immunoprophylaxis, general practitioners, vaccine-preventable diseases, public health

\section{INTRODUCTION}

At this stage of development of society, the immunoprophylaxis is one of the most costeffective health interventions which lead to a reduced level of morbidity, disability and mortality caused by vaccine preventable infections.

The high health efficiency of vaccine programs all over the world in Europe provides prevention to millions of children against a number of serious infectious diseases and prevents about 2-3 million of deaths per year (1).

\footnotetext{
*Correspondence to: Chief assist.prof. Dr. Eliyana Ivanova, DM, Medical University „Prof. Dr. P. Stoyanov" - Varna, Faculty of Public Health, Department of Hygiene and Epidemiology, 55 Marin Drinov Str., Varna 9002, e-mail:

The achievement of a high coverage of vaccinated children (more than $90 \%$ ) worldwide is a major priority for all the WHO member states as established in the approved Global Vaccine Action Plan 2011-2020 (2). The Republic of Bulgaria as an active member of the international health organizations works hard for the realization of The European Vaccine Action Plan including strengthening and achieving of financial sustainability of national immunization programmes, eliminating measles and rubella, maintaining the poliomyelitis-free status of the European Region $(2,3,4)$.

In the recent years there is a decrease in the immunization coverage worldwide and in Europe, i.e. a ratio below the optimal threshold regarding the vaccine preventable infections $86 \%$ of global coverage of DTP3 in babies, 85 $\%$ of MMR first intake and $61 \%$ of MMR 
second intake, HBV - $83 \%$ (5) and below 84 $\%$ of the immunization coverage for measles in a number of European countries (6). The periodically emerging mass morbidity cycles of measles in Italy, Greece, France, Romania; diphtheria in Latvia, France, Great Britain; whooping cough - Germany, Great Britain, Poland, the Netherlands, arise out of insufficient herd immunity and question the realization of the valid international programmes aimed at low morbidity, elimination and eradication (7).

The realization of the vaccination policy in the country depends directly on competence of the general practitioners and neonatologists who are the main executors of the national immunization programme. The confidence of parents in the benefits of vaccines regarding their children's health is another major factor contributing to the immunization coverage.

\section{MATERIALS AND METHODS}

A survey has been conveyed for the period from March 1, 2017 to March 30, 2017 among
IVANOVA E., et al. 127 recipients including 113 general practitioners and 14 neonatologists from Varna Region. An individual inquiry card has been used comprising 7 closed and 6 open questions. Epidemiological, sociological, mathematical and statistical methods have been applied in the data analysis and processing.

\section{RESULTS}

Regarding the mandatory vaccination issue in the Republic of Bulgaria, $83 \%$ of the general practitioners and neonatologists consider that vaccines shall be mandatory, thus supporting the national immunization policy in the country.

$71 \%$ of the respondents report that there are parents in their practices who refuse vaccines. Prior to vaccination the parents are mainly concerned about serious adverse reactions and possible harm due to vaccine application. The parents are interested in the vaccine origin and the level of safety proved by the manufacturer in the broad use (Figure 1).

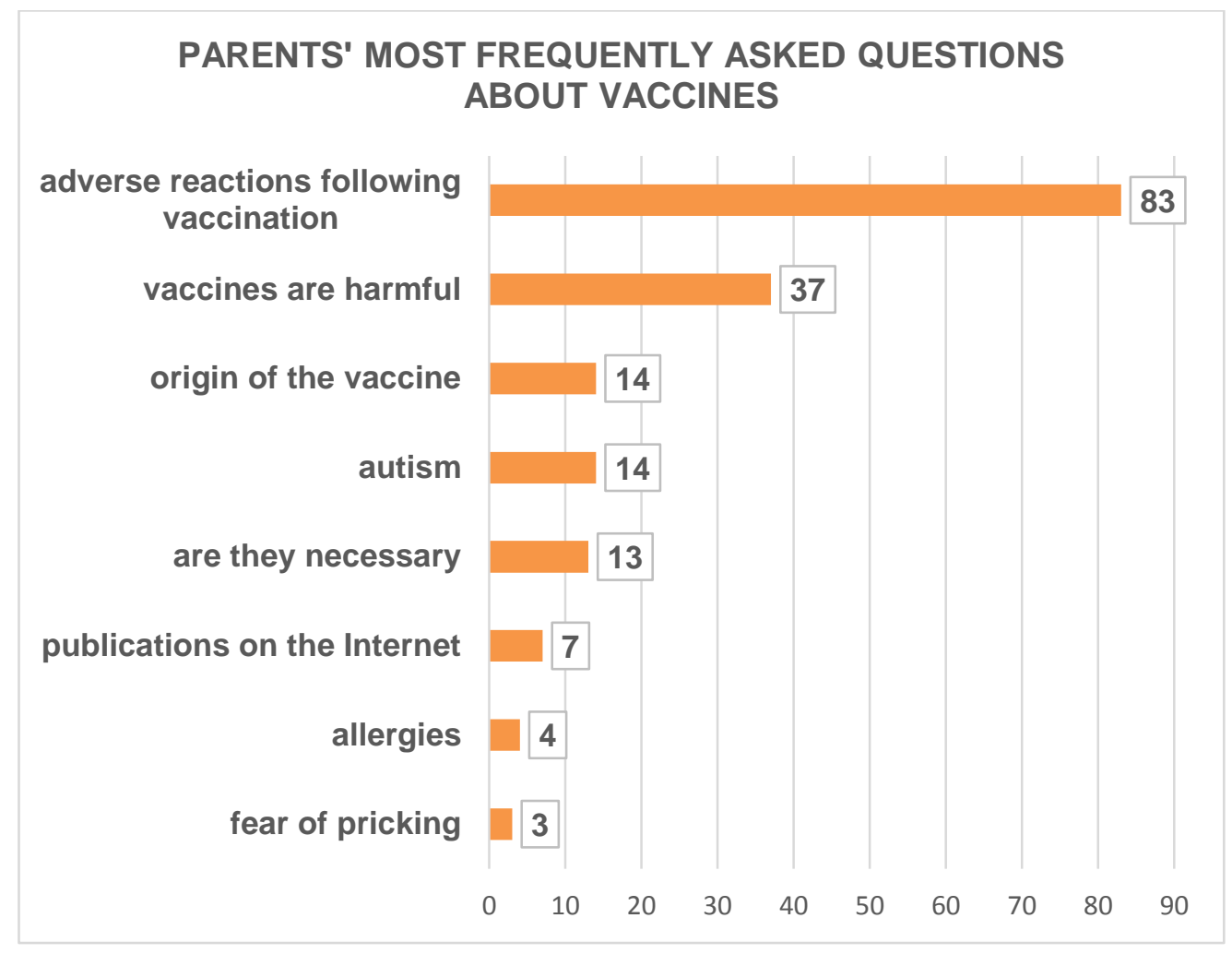

Figure 1. Parents most frequently asked questions about vaccines

The difficulties suffered by the GPs regarding the coverage of elderly population who are subject to immunization are related to failure to show on time, refusal or unwillingness to be vaccinated which is visible in the responses of $59.05 \%$ of the physicians. $15,6 \%$ of the GPs report that the non-coverage is due to an address registration and telephone change, or to immigration abroad (Figure 2).
The most common reason why GPs and neonatologists postpone planned immunization and re-immunization to the relevant contingents are temporary contraindications, which are compensated for up to 3 months. Postponement of immunizations due to lack and irregular supply of vaccines was reported by $36.2 \%$ of the respondents (Figure 3). 


\section{DIFFICULTIES ENCOUNTERED BY GPS IN DEALING WITH ADULTS WITH COMPULSORY REIMMUNIZATION}

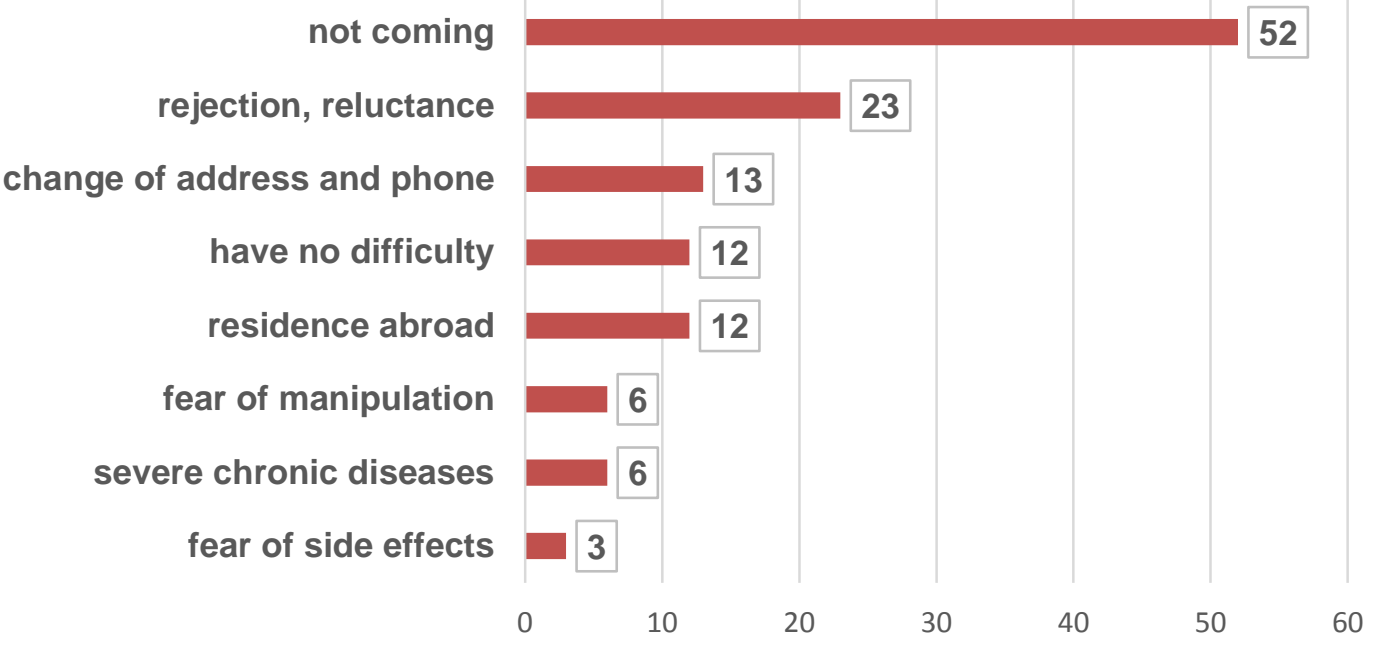

Figure 2. Difficulties encountered by GPs in dealing with adults with compulsory reimmunization

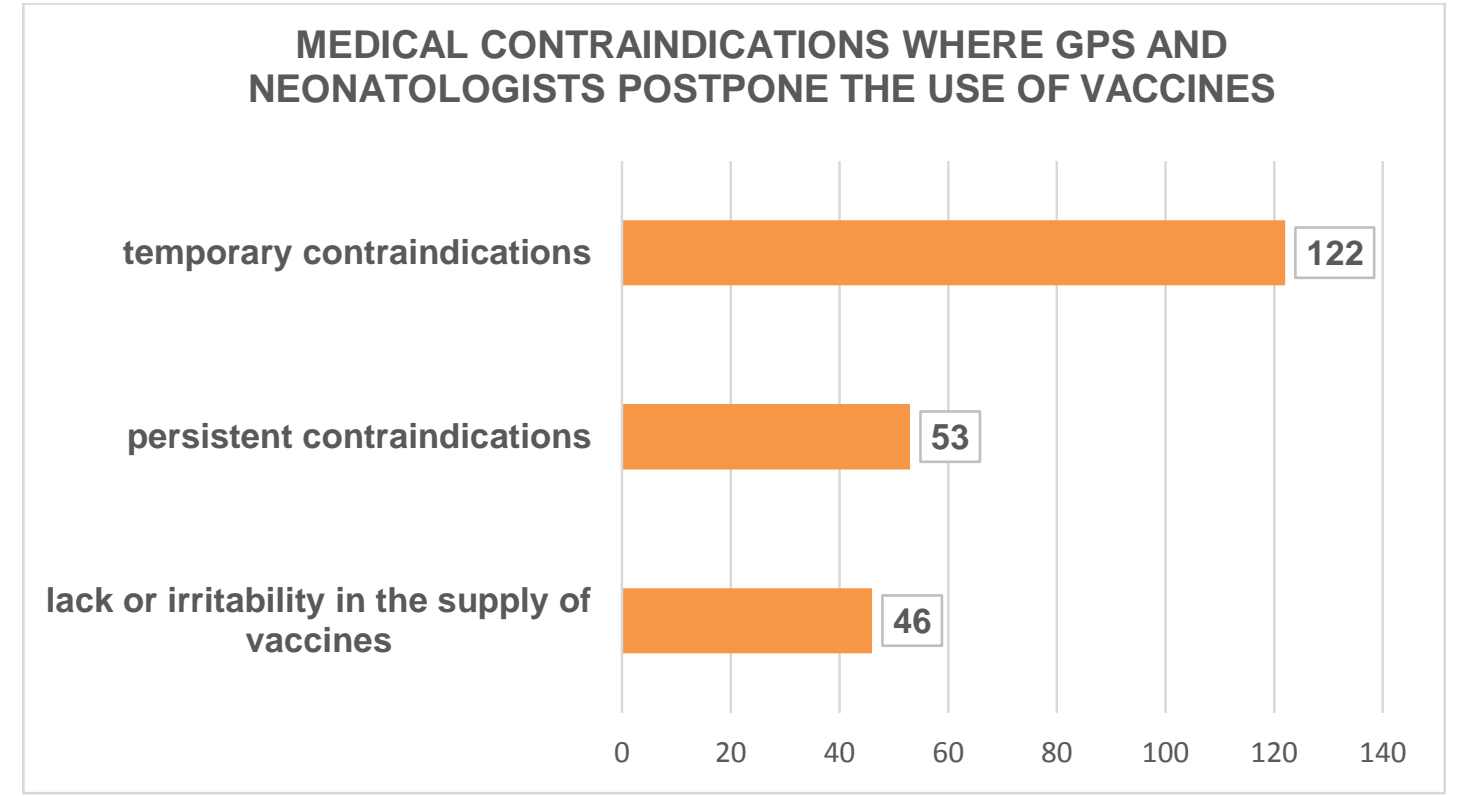

Figure 3. Medical contraindications where GPs and neonatologists postpone the use of vaccines

The observed adverse reactions after vaccination are reduced to the standard for one post-vaccine process - a local inflammatory reaction and fever. Reports of rash, irritability, and changes in child's appetite are single (Figure 4).

Regarding the completion of post-vaccination adverse reaction forms, $85 \%$ of respondents were informed where, how and to whom they should address. $5.5 \%$ of GPs said they did not know about this form and had no information. Neonatologists report a lack of feedback from parents or GPs and failure to monitor the adverse reactions.
More than half of the GPs $(55.1 \%)$ want an informed consent for the administration of vaccines to be introduced and $85.7 \%$ of the neonatologists wish it to be introduced and used in the maternity homes.

Every third of the physicians surveyed believed in the safety of vaccines they administer. Communicating with parents about the risks and benefits of immune prophylaxis does not cause problems for $91.34 \%$ of physicians. About 95\% of GPs and neonatologists know reliable sources of information about vaccines and vaccine prophylaxis. However, almost half of the respondents share the need for subsequent postgraduate training in immune prophylaxis (Figure 5). 


\section{THE MOST COMMON ADVERSE REACTIONS FOLLOWING \\ VACCINATION SEEN BY GPS AND NEONATOLOGISTS}

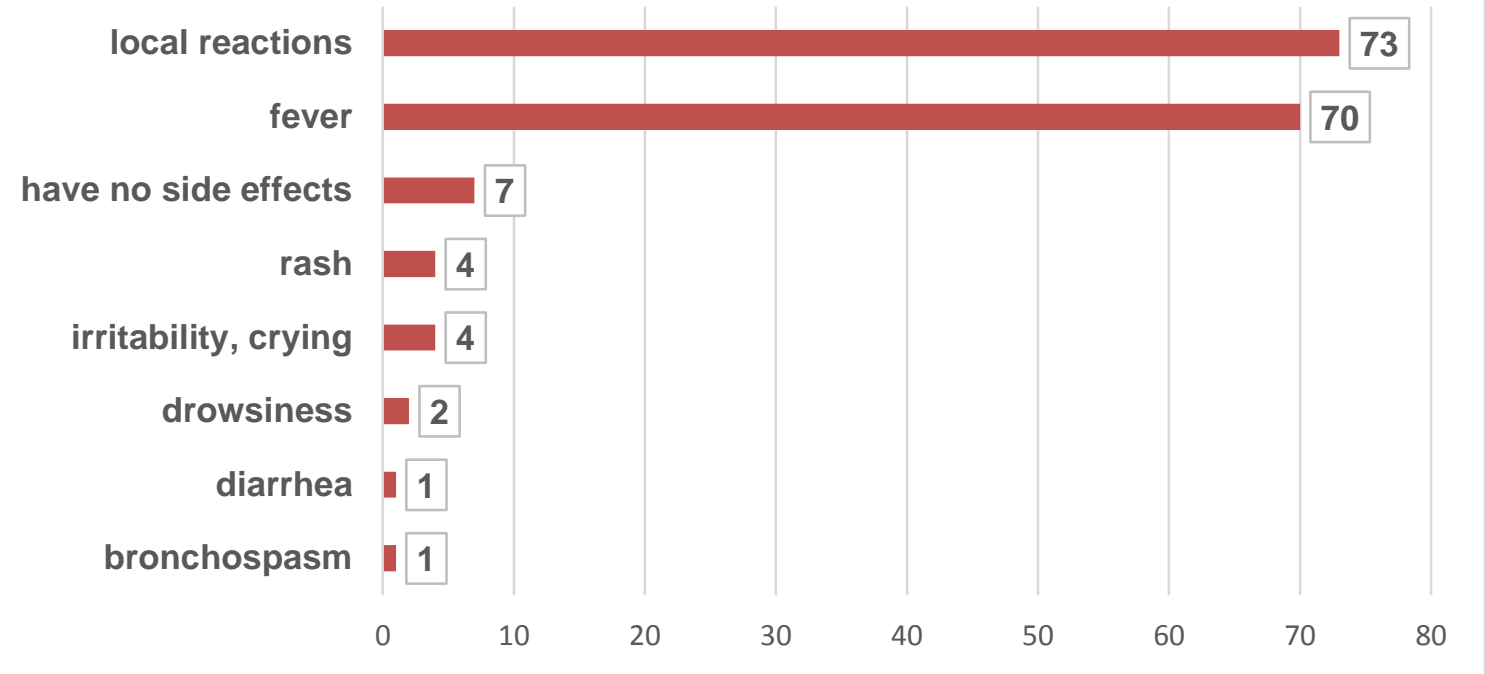

Figure 4. The most common adverse reactions following vaccination seen by GPs and

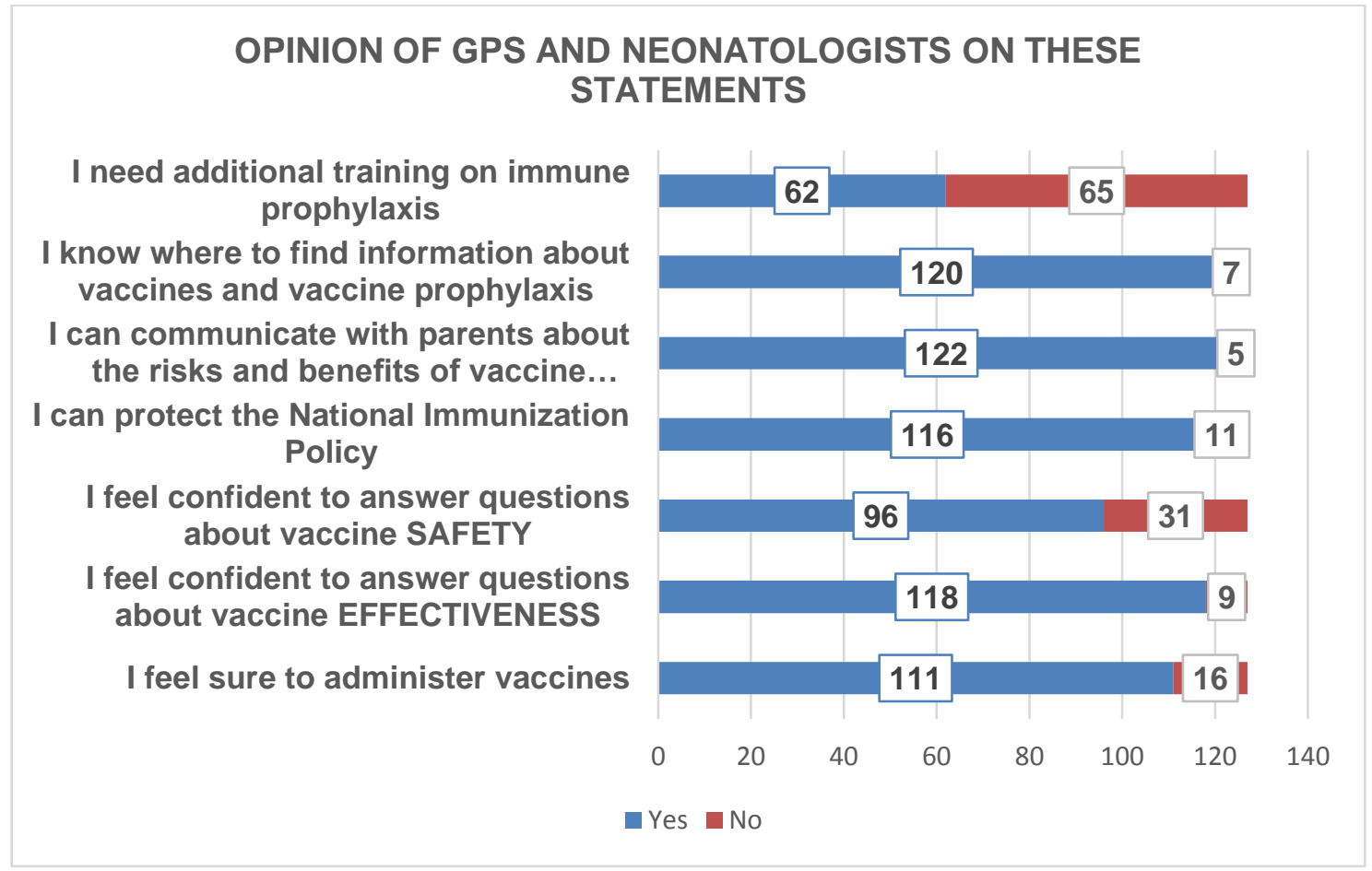

Figure 5. Opinion of GPs and neonatologists on these statements

\section{CONCLUSIONS}

GPs and neonatologists in Varna Region consider that vaccines included in the Immunization Schedule of Bulgaria should be mandatory. They believe in the practical application of vaccines and can fulfill and protect the national immunization policy and communicate with parents on issues related to the safety and effectiveness of vaccines. About half of GPs and neonatologists point out the need for further and subsequent training of medical professionals, participating in the immune prophylaxis system in the country.

\section{REFERENCES}

1. WHO, Media centre, Immunization coverage, $2016 \quad$ [Internet] http://www.who.int/mediacentre/factsheets/ fs $378 / \mathrm{en} /$

2. WHO. Global vaccine action plan 20112020

[Internet].http://www.who.int/immunization /global_vaccine_action_plan/GVAP_doc_2 011_2020/en/

3. WHO, Immunization highlights: European Vaccine Action Plan progress report for 2016, [Internet], http://www.euro.who.int/en/healthtopics/disease-prevention/vaccines-and- 
immunization/publications/2017/immunizat ion-highlights-european-vaccine-actionplan-progress-report-for-2016

4. WHO, Vaccines and immunization, [Internet]

http://www.euro.who.int/en/healthtopics/disease-prevention/vaccines-andimmunization/vaccines-and-immunization

5. WHO, Global immunization coverage 2016,

[Internet]

http://www.who.int/en/news-room/factsheets/detail/immunization-coverage
IVANOVA E., et al.

6. ECDC, Vaccination coverage for the second dose of measles-containing vaccine by country, 2016, WHO, EU/EEA countries, [Internet] https://ecdc.europa.eu/en/publicationsdata/vaccination-coverage-second-dosemeasles-containing-vaccine-country-2016who-6

7. ECDC, Surveillance Atlas of Infectious Diseases, 2018

[Internet], http://atlas.ecdc.europa.eu/public/index.asp $\mathrm{X}$ 